\title{
Relieving suffering or intentionally hastening death: Where do you draw the line?*
}

\author{
Charles L. Sprung, MD; Didier Ledoux, MD; Hans-Henrik Bulow, MD; Anne Lippert, MD; \\ Elisabet Wennberg, MD, PhD; Mario Baras, PhD; Bara Ricou, MD; Peter Sjokvist, $†$ MD; Charles Wallis, MD; \\ Paulo Maia, MD; Lambertius G. Thijs, MD; Jose Solsona Duran, MD; and the ETHICUS Study Group
}

Objective: End-of-life practices vary worldwide. The objective was to demonstrate that there is no clear-cut distinction between treatments administered to relieve pain and suffering and those intended to shorten the dying process.

Design: Secondary analysis of a prospective, observational study. tries.

Setting: Thirty-seven intensive care units in 17 European coun-

Patients: Consecutive patients dying or with any limitation of therapy.

Interventions: Evaluation of the type of end-of-life category; dates and times of intensive care unit admission, death, or discharge; and decisions to limit therapy, medication, and doses used for active shortening of the dying process and the intent of the doctors prescribing the medication.

Measurements and Main Results: Limitation of life-sustaining therapy occurred in $3,086(72.6 \%)$ of 4,248 patients, and $94(2.2 \%)$ underwent active shortening of the dying process. Medication for active shortening of the dying process included administration of opiates (morphine to 71 patients) or benzodiazepines (diazepam to 54 patients) alone or in combination. The median dosage for morphine was $25.0 \mathrm{mg} / \mathrm{hr}$ and for diazepam $20.8 \mathrm{mg} / \mathrm{hr}$. Doses of opiates and benzodiazepines were no higher than mean doses used with withdrawal in previous studies in 20 of $\mathbf{6 6}$ patients and were within the ranges of doses used in all but one patient. Doctors considered that medications for active shortening of the dying process definitely led to the patient's death in 72 patients $(77 \%)$, probably led to the patient's death in $11(12 \%)$, and were unlikely to have led to death in $11(12 \%)$ patients.

Conclusions: There is a gray area in end-of-life care between treatments administered to relieve pain and suffering and those intended to shorten the dying process. (Crit Care Med 2008; 36:8-13)

Key WoRds: end-of-life decisions; euthanasia; shortening the dying process; withdrawing treatment; intensive care units; double effect

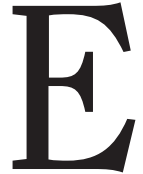

nd-of-life actions are common in intensive care units (ICUs) around the world (1-4). Despite a widespread perception of excessive and inappropriate use of lifesustaining technology, withholding or withdrawing of treatment occurs in more than two thirds of patients dying in ICUs $(1,4)$ and has actually increased (5). The use of aggressive therapy has decreased

\footnotetext{
*See also p. 331.

†Deceased.

From the Department of Anesthesiology and Critical Care Medicine (CLS), Hadassah Hebrew University Medical Center, Jerusalem, Israel; Department of Anesthesiology and Intensive Care Medicine (DL), University of Liege, Liege, Belgium; Department of Anesthesiology (HHB), University Hospital of Glostrup, Glostrup, Denmark; Department of Anesthesiology (AL), Herlev University Hospital, Herlev, Denmark; Department of Anesthesia and Intensive Care (EW), Sahlgrenska University Hospital, Gothenburg, Sweden; The Hebrew University-Hadassah School of Public Health (MB) Hadassah Hebrew University Medical Center, Jerusalem; Department of Anesthesiology, Pharmacology and Intensive Care (BR), Geneva University Hospital, Geneva, Switzerland; Department of Anesthesiology (PS),
}

(5-7). While in the past most patients died in ICUs after cardiopulmonary resuscitation (CPR) (8), presently only approximately $20 \%$ of ICU patients who die undergo CPR $(1,4)$.

Discussions of end-of-life practices in ICUs generally imply that the lines between these practices are clear and well defined. Actions undertaken in the care of dying patients are grouped into distinct categories, including $\mathrm{CPR}$, withholding or withdrawing treatment, and active euthanasia or active shortening of the dying process (SDP) (1-5). Active euthanasia or SDP is assumed to be distinct from legal and ethically acceptable practices, such as withholding and withdrawing treatment.

Even though limitation of therapy is common, active euthanasia is controversial and only legal in The Netherlands and
Orebro University Hospital, Orebro and Huddinge University Hospital, Stockholm, Sweden; Department of Anesthesiology (CW), Western General Hospital, Edinburgh, United Kingdom; Department of Intensive Care (PM), Hospital Geral Santo Antonio, Porto, Portugal; Department of Medicine (LGT), VU Hospital, Amsterdam, The Netherlands; and Department of Anesthesiology (JSD), Hospital del Mar, Barcelona, Spain.

Funded as part of the European Concerted Action project ETHICUS-"End of Life Decision Making and Life Ending Procedures in European Intensive Care Units" funded by the European Commission (contract PL 963733); in part by grant 4226 from the Chief Scientist's Office of the Ministry of Health, Israel; in part by OFES Switzerland (Biomed) 980271; in part by the European Society of Intensive Care Medicine; and in part by the Walter F. and Alice Gorham Foundation.
The authors are solely responsible for the publication; it does not represent the opinion of the European Commission, and the commission is not responsible for any use of the published data.

The authors have not disclosed any potential conflicts of interest.

Address requests for reprints to: Charles L. Sprung, MD, General Intensive Care Unit, Department of Anesthesiology and Critical Care Medicine, Hadassah Hebrew University Medical Center, P.0. Box 12000, Jerusalem, Israel 91120. E-mail: sprung@cc. huji.ac.il

Copyright (C) 2007 by the Society of Critical Care Medicine and Lippincott Williams \& Wilkins

DOl: 10.1097/01.CCM.0000295304.99946.58 
Belgium (on the patient's direct request) $(9,10)$, and physician-assisted suicide is only allowed in Switzerland and Oregon in the United States (11). In these countries, where the law defines euthanasia as the act of deliberately terminating the life of another person at his or her request, active euthanasia practiced in the ICU for incompetent patients would be viewed as illegal. Palliative care, on the other hand, is widely practiced and encouraged (12). It is well known that the same medications given to ease pain and suffering can potentially cause or hasten death. It is exceedingly difficult to determine whether and when relief measures are undertaken with the implicit or explicit intention to shorten the dying process as opposed to just relieve pain and suffering.

Only three studies have examined the use of life-shortening practices in adult ICUs. In an attitudinal survey conducted in 16 European countries, $40 \%$ of physicians admitted to sometimes deliberately administering drugs to patients with no hope of survival until death ensues (13). The ETHICUS study documented SDP in seven of 17 European countries (4). Asch (14) noted that $17 \%$ of critical care nurses were asked by patients or relatives to perform euthanasia or assist in suicide, and 16\% reported that they had engaged in such practices.

The purpose of this article is to make the argument and show evidence that there is no clear-cut distinction between treatments administered to relieve pain and suffering when withdrawing lifesustaining treatment and those intended to shorten the dying process. An in-depth examination of this gray area in end-oflife care has important moral and ethical implications for the practice of intensive care medicine. It also has implications for other acute care areas, long-term care, and community care, where there are similar concerns about pain management vs. actively assisting in the dying process. The article elaborates on the previous report (4), which only briefly touched on the findings on SDP. It analyzes the overlap between SDP and other end-of-life practices relying on three variables: doses of potentially life-shortening intravenous drugs, the time for patients to die after limitation of therapy, and the intent of the doctors who prescribed the medications.

\section{METHODS}

Study Population. This report is a secondary analysis of a previous prospective study (4). All consecutive adult patients who died or had any limitation of lifesaving interventions in the ICU from January 1, 1999, to June 30, 2000, were studied prospectively (4). Patients were followed until discharge from ICU, death, or 2 months from the decision to limit therapy (4).

Definitions of End-of-Life Categories. Endof-life categories were defined prospectively as CPR, brain death, withholding life-sustaining treatment, withdrawing life-sustaining treatment, and SDP as previously reported (4). SDP was defined in the questionnaire as a circumstance in which someone performed an act with the specific intent of shortening the dying process. These acts did not include withholding or withdrawing treatment, and examples included intentional overdose of narcotics, anesthetics, or potassium chloride (4). A hierarchy for categorizing patients used the more active mode of limitation if more than one was recorded. Patients were classified as "withhold" only if that was the sole limitation made; "withdraw" included patients for whom treatment was both withheld and withdrawn; and "SDP" included cases involving withholding or withdrawing and SDP decisions.

Ethical and Legal Considerations. No interventions or treatments were given, withheld, or withdrawn from patients as part of the initial observational study (4). Countries, centers, and study patients were coded anonymously to ensure confidentiality and to allow clinicians to report practices of questionable legality. Individual institutional ethics committee approval with a waiver of informed consent was required and obtained from each participating institution.

Study Centers and Data Collection. National representatives of the Ethics Section of the European Society of Intensive Care Medicine coordinated the study for each country's participating ICUs. The prospectively collected data used specifically for this secondary analysis included type of end-of-life category (SDP and other categories were self-identified by the responsible physician) and dates and times of 1) ICU admission; 2) death or discharge; and 3) decisions to limit therapy, medication, and doses used for SDP and the intent of the doctors prescribing the medication or extubation. Physicians retrospectively classified the acts used for SDP as definitely, probably, or probably not the cause of the patient's death.

Statistical Analyses. Relative potency scales for analgesics were expressed in parenteral morphine equivalents $(10 \mathrm{mg}$ of morphine sulfate $=0.15 \mathrm{mg}$ of fentanyl citrate $=$ $0.0075 \mathrm{mg}$ of sufentanil citrate) and sedatives in parenteral diazepam equivalents $(10 \mathrm{mg}$ of diazepam $=5 \mathrm{mg}$ of midazolam) $(3,15)$. Drug doses were bolus or cumulative doses given over time. Differences in the numbers of withdrawals of endotracheal tubes were tested with the Fisher's exact test, and times from withdrawal of endotracheal tubes until death were tested by the Mann-Whitney test. Descriptive statistics for time variables are presented as median and interquartile range (IQR). Those variables are markedly skewed, and therefore differences were tested using the nonparametric Kruskal-Wallis rank test. The Cox proportional-hazards model was used to evaluate the association between drug doses and time from SDP to death. The hazard ratios are expressed for a $10-\mathrm{mg} / \mathrm{hr}$ increase of either morphine or diazepam. Differences were considered significant if $p<.05$.

\section{RESULTS}

During the initial study, 31,417 patients were admitted to ICUs in 37 centers located in 17 countries (4). Of the 31,417 patients, 4,248 who died or had limitations of life-sustaining treatments comprised the study population. Limitation of life-sustaining therapy occurred in $3,086(72.6 \%)$ of 4,248 patients, $9.8 \%$ of all ICU admissions, and $76.0 \%$ of dying patients. The frequencies of the different end-of-life categories were as follows: 832 $(19.6 \%)$ of the patients received CPR, 330 $(7.8 \%)$ were diagnosed with brain death, $1,594(37.5 \%)$ had therapies withheld, $1,398(32.9 \%)$ had therapies withdrawn, and $94(2.2 \%)$ underwent SDP.

All SDP patients already had previous therapies withheld or withdrawn. SDP was performed in nine of the 37 centers in seven of the 17 countries, which was a minority of centers. Of the SDP patients, types of medications were available for all patients, and doses used for SDP were available for $66(70 \%)$ patients. Table 1 demonstrates the medications and doses used (if available), the time from SDP until death, and whether the doctor administering the medication believed it caused the patient's death. Treatment modalities used for the patients who underwent SDP included administration of opiates or benzodiazepines alone or in combination; four patients also received muscle relaxants and seven received barbiturates. Potassium chloride was not used in any of the SDP cases. The most commonly used opiate was morphine (administered to 71 patients alone or in combination), ranging from 5 to $200 \mathrm{mg}$. The most commonly used benzodiazepine was diazepam (administered to 54 patients alone or in combination), ranging from 20 to $200 \mathrm{mg}$. The median dosage for morphine was $25.0 \mathrm{mg} / \mathrm{hr}$ and for diazepam $20.8 \mathrm{mg} / \mathrm{hr}$. Although mean doses of opiates and benzodiazepines used for SDP were higher than mean doses used with withdrawing in previous studies $(2,3)$, they were no higher in 20 of 66 patients and were within the ranges of doses used in all but one patient (Table 
Table 1. Active shortening of the dying process (SDP): medications, doses in morphine and diazepam equivalents (mg/hr), time from SDP until death, and whether SDP caused death

\begin{tabular}{|c|c|c|c|c|c|}
\hline & Medication & $\begin{array}{c}\text { Morphine, } \\
\text { mg/hr }\end{array}$ & $\begin{array}{l}\text { Valium, } \\
\mathrm{mg} / \mathrm{hr}\end{array}$ & $\begin{array}{l}\text { Time from SDP } \\
\text { to Death, hrs }\end{array}$ & $\begin{array}{l}\text { SDP Caused } \\
\text { Death }^{a}\end{array}$ \\
\hline 1 & Morphine, diazepam & & & 1.5 & 1 \\
\hline 2 & Sufentanil & 33.4 & & 7.5 & 1 \\
\hline 3 & Morphine, diazepam & & & 1.75 & 1 \\
\hline 4 & Morphine & & & 3.9 & 1 \\
\hline 5 & Morphine, diazepam & & & 6.0 & 1 \\
\hline 6 & $\begin{array}{l}\text { Morphine, diazepam, } \\
\text { pancuronium }\end{array}$ & 11.7 & 5.9 & 8.5 & 1 \\
\hline 7 & Morphine, diazepam & 38.5 & 15.4 & 1.3 & 1 \\
\hline 8 & Morphine, diazepam & 10.5 & 21.1 & 4.75 & 1 \\
\hline 9 & Sufentanil & 66.7 & & 1.5 & 1 \\
\hline 10 & Morphine, diazepam & 33.3 & 33.3 & 3.0 & 1 \\
\hline 11 & Morphine, diazepam & 7.1 & 35.7 & 7.0 & 1 \\
\hline 12 & Morphine & & & 2.5 & 1 \\
\hline 13 & Morphine, diazepam & & & 1.3 & 1 \\
\hline 14 & Morphine, diazepam & & & 4.25 & 1 \\
\hline 15 & Morphine, diazepam & 59.9 & & 1.67 & 1 \\
\hline 16 & Morphine, diazepam & 44.4 & 44.4 & 2.25 & 1 \\
\hline 17 & Sufentanil, midazolam & 66.9 & 20.4 & 2.75 & 1 \\
\hline 18 & Morphine, diazepam & & & 1.5 & 1 \\
\hline 19 & Morphine, diazepam & 66 & 40 & 0.5 & 1 \\
\hline 20 & Morphine, diazepam & 14.3 & 14.3 & 3.5 & 1 \\
\hline 21 & Sufentanil & 167.2 & & 1.5 & 1 \\
\hline 22 & Morphine, diazepam & 10.5 & 42.1 & 4.75 & 1 \\
\hline 23 & Sufentanil, midazolam & & & 2.9 & 1 \\
\hline 24 & Sufentanil, midazolam & 33.4 & 13.3 & 3.0 & 1 \\
\hline 25 & Morphine, diazepam & & & 0.4 & 1 \\
\hline 26 & Sufentanil, diazepam & 66.7 & 16.7 & 3.0 & 1 \\
\hline 27 & Sufentanil, diazepam & 42 & 15 & 2.0 & 1 \\
\hline 28 & $\begin{array}{l}\text { Morphine, diazepam, } \\
\text { thiopental }\end{array}$ & 19 & 38.1 & 5.25 & 1 \\
\hline 29 & Morphine, diazepam & & & 12.4 & 1 \\
\hline 30 & Morphine, diazepam & 30 & 30 & 2.0 & 1 \\
\hline 31 & Morphine, diazepam & 120 & 120 & 2.0 & 1 \\
\hline 32 & Morphine, diazepam & & & 6.0 & 1 \\
\hline 33 & Morphine, diazepam & 20.4 & 20.4 & 4.9 & 1 \\
\hline 34 & Sufentanil, pentothal & 3.8 & & 1.75 & 1 \\
\hline 35 & Morphine, diazepam & 200 & 200 & 0.5 & 1 \\
\hline 36 & Sufentanil & 100.1 & & 3.0 & 1 \\
\hline 37 & $\begin{array}{l}\text { Morphine, diazepam, } \\
\text { thiopental }\end{array}$ & 160 & 160 & 0.5 & 1 \\
\hline 38 & $\begin{array}{l}\text { Morphine, diazepam, } \\
\text { cisatracurium }\end{array}$ & 25 & 25 & 4.0 & 1 \\
\hline 39 & $\begin{array}{l}\text { Morphine, diazepam, } \\
\text { cisatracurium }\end{array}$ & 16.3 & 4.1 & 12.3 & 1 \\
\hline 40 & Morphine, diazepam & & & 5.0 & 1 \\
\hline 41 & Morphine, diazepam & 125 & 125 & 0.4 & 1 \\
\hline 42 & Morphine, diazepam & & & 2.0 & 1 \\
\hline 43 & Morphine, diazepam & & & 2.75 & 1 \\
\hline 44 & Morphine & & & 0.5 & 1 \\
\hline 45 & Morphine, propofol & & & 1.75 & 1 \\
\hline 46 & Morphine, diazepam & 11.8 & 7.8 & 12.75 & 1 \\
\hline 47 & Morphine & & & 1.0 & 1 \\
\hline 48 & Morphine, diazepam & 25 & 30 & 2.0 & 1 \\
\hline 49 & Morphine, thiopental & 800 & & 0.25 & 1 \\
\hline 50 & Diazepam & & & 3.5 & 1 \\
\hline 51 & $\begin{array}{l}\text { Morphine, diazepam, } \\
\text { thiopental }\end{array}$ & 100 & 200 & 0.1 & 1 \\
\hline 52 & Morphine, diazepam & 90.9 & & 1.1 & 1 \\
\hline 53 & Morphine, diazepam & 10 & 10 & 5.0 & 1 \\
\hline 54 & Morphine & 74.6 & & 0.67 & 1 \\
\hline 55 & Morphine, diazepam & 12.5 & 7.5 & 4.0 & 1 \\
\hline 56 & Morphine & 100 & & 1.0 & 1 \\
\hline 57 & $\begin{array}{l}\text { Cisatracurium, } \\
\text { morphine }\end{array}$ & & & 0.1 & 1 \\
\hline 58 & Morphine, diazepam & 12.5 & & 4.0 & 1 \\
\hline 59 & Morphine, diazepam & 25 & & 2.0 & 1 \\
\hline
\end{tabular}

2). In retrospect, doctors considered that the doses of medications they gave for SDP definitely led to the patient's death in 72 patients $(77 \%)$, probably led to the patient's death in $11(12 \%)$, and were unlikely to have led to the patients death in $11(12 \%)$ (Table 1).

Withdrawal of endotracheal tubes occurred in 17 of the 94 SDP patients (18.1\%) and $125(8.9 \%)$ of 1,398 patients who underwent withdrawal of treatment $(p=.01)$. In the SDP patients, the median (IQR) time from the withdrawal of endotracheal tubes until death was 7.0 hrs (12.4 hrs) vs. 3.5 hrs (6.6 hrs) from the time of all other withdrawals of treatments until death $(p<.05)$. There was no difference in the median time to death in the seven patients with prior limitations before withdrawal of endotracheal tube42.0 hrs (63.6 hrs)—vs. the ten patients without prior limitations $-50.0 \mathrm{hrs}$ (129.3 hrs).

The median (IQR) time from the first decision to limit treatment until death was $14.7 \mathrm{hrs}$ ( $51.0 \mathrm{hrs})$. The median (IQR) time from the decision for the most active form of limitation of therapy until death was $6.6 \mathrm{hrs}$ (30.2 hrs) for all patients, 14.3 hrs (64.6 hrs) for withholding, $4.0 \mathrm{hrs}$ (16.2 hrs) for withdrawing, and $3.5 \mathrm{hrs}(7.0 \mathrm{hrs})$ for SDP $(p<.001)$. Increasing doses of opiates and benzodiazepines were associated with a shorter time to death (hazard ratio for morphine, 1.10; 95\% confidence interval, 1.04-1.16; hazard ratio for diazepam, 1.12; 95\% confidence interval, 1.03-1.22) (Fig. 1).

\section{DISCUSSION}

Although end-of-life medical actions are commonly grouped into distinct categories, in actual practice they form a continuum-from aggressive resuscitation to active euthanasia-and the dividing lines between different actions are not always easy to define. A thorough and frank discussion of the differences, similarities, and overlaps between different end-of-life practices is vital to ensure optimal and responsible critical care.

An example of the complexity in defining different categories of ICU care is the relationship between withholding and withdrawing life-sustaining therapies. The conventional ethical view is that there is no moral distinction between the two (13), but this belief is not universal (16), and studies show that some healthcare professionals are more reluctant to withdraw than withhold therapies (13, 
Table 1. - Continued

\begin{tabular}{|c|c|c|c|c|c|}
\hline & Medication & $\begin{array}{l}\text { Morphine, } \\
\text { mg/hr }\end{array}$ & $\begin{array}{l}\text { Valium, } \\
\mathrm{mg} / \mathrm{hr}\end{array}$ & $\begin{array}{l}\text { Time from SDP } \\
\text { to Death, hrs }\end{array}$ & $\begin{array}{l}\text { SDP Caused } \\
\text { Death }^{a}\end{array}$ \\
\hline 60 & $\begin{array}{l}\text { Morphine, diazepam, } \\
\text { thiopental }\end{array}$ & 250 & 250 & 0.2 & 1 \\
\hline 61 & Thiopental & & & 0.2 & 1 \\
\hline 62 & Morphine, diazepam & & & 6.6 & 1 \\
\hline 63 & Sufentanil & 66.7 & & 2.0 & 1 \\
\hline 64 & Morphine, diazepam & 7.7 & 7.7 & 13.0 & 1 \\
\hline 65 & Sufentanil, midazolam & 133.4 & 40 & 3.25 & 1 \\
\hline 66 & Sufentanil, diazepam & 100.1 & 100 & 2.0 & 1 \\
\hline 67 & Morphine, diazepam & 11.4 & 11.4 & 3.5 & 1 \\
\hline 68 & Morphine, diazepam & 20 & 20 & 5.0 & 1 \\
\hline 69 & Morphine, diazepam & 37.5 & 37.5 & 4.0 & 1 \\
\hline 70 & Diazepam & & 44.4 & 2.25 & 1 \\
\hline 71 & Morphine & 1.2 & & 25.0 & 1 \\
\hline 72 & Morphine & 30 & & 1.5 & 1 \\
\hline 73 & Sufentanil, diazepam & & & 8.0 & 2 \\
\hline 74 & Morphine, diazepam & & & 3.1 & 2 \\
\hline 75 & Morphine, diazepam & 3.4 & 3.4 & 11.75 & 2 \\
\hline 76 & Morphine & 7.5 & & 10.0 & 2 \\
\hline 77 & Benzodiazepine, opioids & & & 0.6 & 2 \\
\hline 78 & Morphine, midazolam & 8 & 16 & 8.75 & 2 \\
\hline 79 & Morphine, midazolam & 10 & 1.1 & 8.5 & 2 \\
\hline 80 & Midazolam & 2.1 & 2.1 & 9.5 & 2 \\
\hline 81 & Morphine & 3.1 & & 6.5 & 2 \\
\hline 82 & Morphine & 8.5 & & 4.25 & 2 \\
\hline 83 & Morphine & 1.2 & & 16.5 & 2 \\
\hline 84 & Morphine & & & 2.6 & 3 \\
\hline 85 & Sufentanil, midazolam & 41.7 & 10 & 1.25 & 3 \\
\hline 86 & Sufentanil & 190.1 & & 4.75 & 3 \\
\hline 87 & Sufentanil & 33.4 & & 1.0 & 3 \\
\hline 88 & Morphine & 10 & & 6.2 & 3 \\
\hline 89 & Fentanyl & 6.7 & & 8.75 & 3 \\
\hline 90 & Morphine & 2.3 & & 22.0 & 3 \\
\hline 91 & Morphine, diazepam & & & 92 & 3 \\
\hline 92 & Fentanyl, propofol & & & 10.65 & 3 \\
\hline 93 & Morphine & 12 & & 0.5 & 3 \\
\hline 94 & Morphine & 0.1 & & 29.1 & 3 \\
\hline
\end{tabular}

${ }^{a}$ Medication definitely (1), probably (2), or probably not (3) caused the patient's death. The median times from SDP to death were 3.0 hrs (for definitely), 8.5 hrs (for probably), and 6.2 hrs (for probably not) $(p<.05)$.

Table 2. Medications given during active shortening of the dying process in ETHICUS and during withholding and withdrawing in other studies

\begin{tabular}{|c|c|c|c|}
\hline & $\begin{array}{l}\text { ETHICUS } \\
(\mathrm{n}=66)\end{array}$ & $\begin{array}{l}\text { Wilson et al. (3) } \\
\qquad(\mathrm{n}=33)\end{array}$ & $\begin{array}{l}\text { Keenan et al. (2) } \\
\quad(n=359)\end{array}$ \\
\hline \multicolumn{4}{|c|}{ Opiate-morphine equivalent $\mathrm{mg} / \mathrm{hr}$} \\
\hline Mean $\pm \mathrm{SD}$ & $59.3 \pm 108.3$ & $11.2 \pm 11.5$ & $21.0 \pm 33.0$ \\
\hline Median & 25 & - & 14.4 \\
\hline Range & $0.1-800$ & - & $0.7-350$ \\
\hline \multicolumn{4}{|c|}{$\begin{array}{c}\text { Benzodiazepine-diazepam } \\
\text { equivalent, mg/hr }\end{array}$} \\
\hline Mean $\pm \mathrm{SD}$ & $46.0 \pm 60.8$ & $9.8 \pm 18.4$ & $8.6 \pm 11.0$ \\
\hline Median & 20.8 & - & 14.4 \\
\hline Range & $1.1-250$ & - & $0.7-350$ \\
\hline
\end{tabular}

17). In fact, different studies have defined not restarting an intravenous vasopressor infusion as either withholding (18) or withdrawing (4).

The blurred line between different categories is also exemplified by the confusion among physicians, which causes them to misclassify or misrepresent their that in fact they had performed withholding of life-sustaining treatment or provided potentially life-shortening narcotics for pain relief, which are neither euthanasia nor assisted suicide (19).

Only one previous study in neonatal ICUs specifically evaluated the controversial overlap between the use of potentially life-shortening drugs and mercy killing (20). Van der Heide et al. (20) found "a rather large overlap between decisions to administer drugs with and without the intention of hastening death, with respect to the type and dose of the drugs given, aspects of decision making, [and] prognostic factors." They reported that potentially life-shortening drugs were given in $37 \%$ of 299 deaths; of these, the possibility that death would be hastened was taken into account in $52 \%$ of patients, hastening of death was partly intended in $22 \%$, and hastening of death was explicitly intended in 26\% (20). All respondents who explicitly intended to hasten death stated that they also acted to alleviate pain or other symptoms (19). Median doses of drugs and length of time by which life was shortened were higher when hastening death was explicitly intended (20). The authors stated that whether drugs were administered with or without the intention of hastening death was not always clear (20). Wilson et al. (3) showed that physicians ordered drugs to hasten death in $39 \%$ of cases but always with other reasons, such as relieving pain. A Dutch governmental multidisciplinary task force on end-of-life decisions also underlined that hastening death in patients may be difficult to distinguish from the palliative effects of drugs (21). The issue is further complicated by the fact that medications given concomitantly with withdrawal of therapy may instead of shortening the time to death actually sometimes delay an inevitable death $(22,23)$.

The purpose of this article is to shed light on one of the most controversial areas in end-of-life practices: the lack of clear or easily determined distinctions between SDP or euthanasia and therapies intended to relieve pain and suffering administered when withdrawing life-sustaining therapies. Differentiation between the two is complicated and may be impossible because the physicians' true intentions are often difficult to ascertain. In an emotionally charged, life-and-death setting, such as the ICU, these intentions are likely to be multilayered, complex, and ambiguous $(12,24,25)$. 


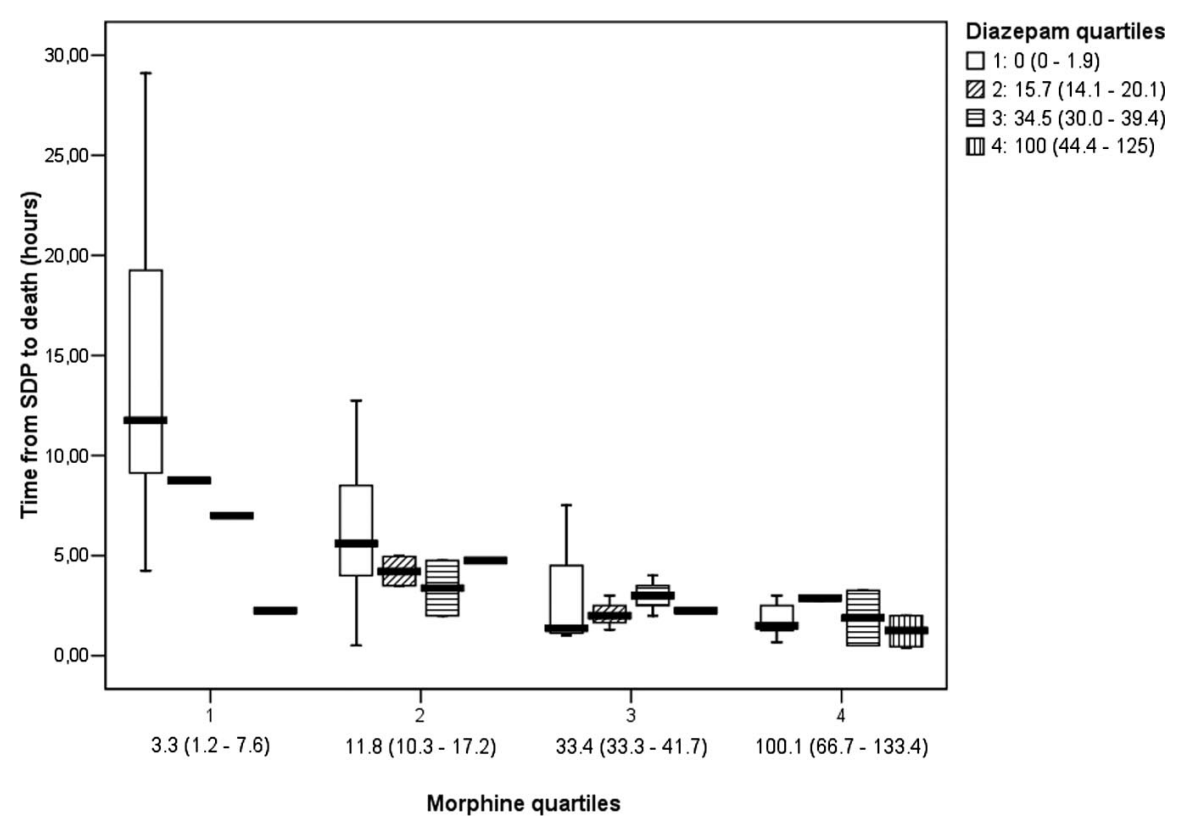

Figure 1. Time from shortening of dying process $(S D P)$ to death according to the doses of the medication (morphine and diazepam equivalents, $\mathrm{mg} / \mathrm{hr}$ ) administered (quartiles). This analysis includes only observations where no drugs other than morphine or diazepam were used.

Intent

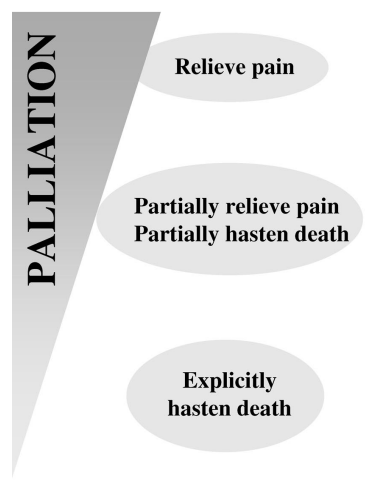

Action

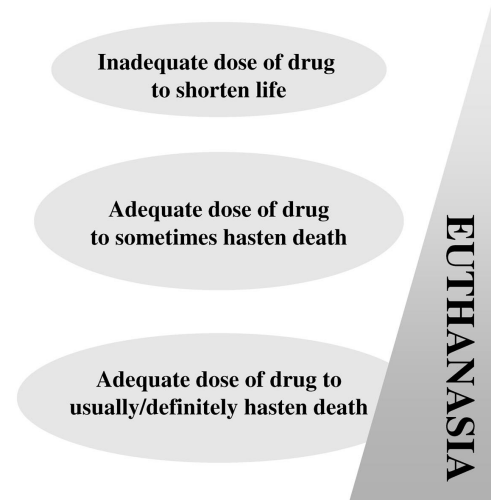

Figure 2. The spectrum of actions between palliative care and euthanasia.

Figure 2 demonstrates the spectrum of actions between palliative care and euthanasia. Palliative care is given to relieve pain and suffering with doses of drugs that are usually inadequate to shorten a patient's life but may at times hasten death without the intent to do so. Euthanasia or SDP occurs when a doctor administers drugs in doses adequate to shorten a patient's life with the explicit intent to hasten death. Differentiation may be difficult as intentions are subjective and private and only self-reporting or an analysis of extreme actions will be determinant (12). This study is one of the few that prospectively recorded the intensivists' intentions along with their practices. The most striking finding of the study was that although doses of opioids and benzodiazepines reportedly used to correlation between higher doses of narcotics and/or benzodiazepines and shorter patient survival $(22,26)$. Although the practices of palliative care and SDP are very different, distinguishing the two may be extremely difficult.

The confusion in end-of-life decisions is also seen within the SDP patients. All doctors explicitly intended to hasten death in SDP patients. In a retrospective evaluation of these actions based on doses of medications given and the length of time until death, the actions were not so clear. Physicians believed that the doses they gave were definitely the cause of death in $77 \%$ of patients, probably the cause in $12 \%$, and probably not the cause in $11 \%$. It is recognized that absolute doses may not be indicative of euthanasia or SDP, because prior exposure, tolerance, and duration of medications are important. Inadequate doses of drugs might be related to a doctor's feelings of guilt or fear of prosecution and may explain the surprising finding that even when SDP was intended, patients took several hours to die, almost as long as cases of in therapy withdrawal. Another unexpected discovery was that extubated patients lived longer than nonextubated patients. These findings suggest that the gray area between relief measures and SDP extends in both directions: While in some cases physicians may be hastening the patient's death by providing what is classified as relief measures, in other cases physicians supposedly intending to cause death may in fact be providing drugs that are only capable of relieving pain and suffering. Therefore, the distinction between therapies intended to relieve pain and suffering and those intended to cause death may not be as clear as previously thought.

A major strength of the present study is that it provides empirical data for an ethical debate that often remains theoretical due to scarcity of facts. Other strong features include the prospective design, enrollment of a large number of consecutive patients from 37 ICUs in 17 countries, evaluation of all limitations and deaths in all admitted patients, and anal$y$ sis of the intent and self-reporting of actions rather than theoretical responses to a questionnaire. Anonymity and contemporaneous documentation probably resulted in honest and more accurate reporting.

There are, however, limitations to the present study. Drug doses were not available for some of the SDP patients and for 
patients who had therapies withheld or withdrawn. There may have been a selection bias in the doses that were reported. In addition, participants by their special interest in ethical issues may not necessarily share the attitudes of unselected ICU physicians. Severity scores of the patients were not analyzed, and underreporting of practices for fear of legal ramifications cannot be excluded.

The present report provides evidence that some physicians may be giving much larger doses of medications than needed for relief of pain or suffering so that the patient can die with dignity, but these physicians do not call this practice euthanasia. Yet in fact, physicians administering these perfectly legal relief treatments may in fact consciously or unconsciously be practicing a disguised form of mercy killing. It is unclear how many physicians or nurses around the world, in providing relief measures to terminal patients, also intend to shorten the dying process.

This complex empirical picture of actual ICU practice, rather than an idealized list of distinct, neatly separated actions, should form the basis for an open discussion of end-of-life practices. We need to arrive at a level of transparency at which proper safeguards for end-of-life medical care $(18,22)$ can be developed and maintained. Palliation with potentially life-shortening drugs may be given with no intent, partial intent, or explicit intent to hasten death. Markedly increasing doses of these drugs may be considered homicide by some and an appropriate form of terminal care by others. Physicians should administer drugs in sufficient amounts to relieve pain and suffering because the importance of palliative care cannot be overemphasized, but the drugs should not be intended to directly cause death (12). Physicians must recognize that appropriate palliative care may lead to a patient's death although unintended. One important safeguard should be proper documentation of the use of potentially life-shortening measures, including keeping records on the timing and doses of the drug and the physician's intention at each step.
Such documentation can help protect the physician wrongly accused of deliberately ending a patient's life. No less important, it may reduce the use of inappropriately large doses of medications to shorten the dying process given in the guise of relieving pain and suffering.

\section{REFERENCES}

1. Prendergast TJ, Claessens MT, Luce JM: A national survey of end-of-life care for critically ill patients. Am J Respir Crit Care Med 1998; 158:1163-1167

2. Keenan SP, Busche KD, Chen LM, et al: A retrospective review of a large cohort of patients undergoing the process of withholding or withdrawal of life support. Crit Care Med 1997; 25:1324-1331

3. Wilson WC, Smedira NG, Fink C, et al: Ordering and administration of sedatives and analgesics during the withholding and withdrawal of life support from critically ill patients. JAMA 1992; 267:949-953

4. Sprung CL, Cohen SL, Sjokvist P, et al: Endof-life practices in European intensive care units. The Ethicus Study. JAMA 2003; 290: 790-797

5. Prendergast TJ, Luce JM: Increasing incidence of withholding and withdrawal of life support from the critically ill. Am J Respir Crit Care Med 1997; 155:15-20

6. Wilson D: A report of an investigation of end-of-life care practices in health care facilities and the influences on those practices. $J$ Palliat Care 1997; 13:34-40

7. Wilson D: Addressing myths about end-of-life care: Research into the use of acute care hospitals over the last five years of life. $J$ Palliat Care 2002; 18:29-38

8. Sprung CL, Eidelman LA, Pizov R: Changes in forgoing life-sustaining treatments in the United States: Concern for the future. Mayo Clin Proc 1996; 71:512-516

9. Van der Maas BJ, Van der Wal, Haver Kate I, et al: Euthanasia, physician- assisted suicide and other medical practices involving end of life in the Netherlands, 1990-1995. N Engl J Med 1996; 335:1699-1705

10. Delliens L, Mortier F, Bilsen J, et al: End-oflife decisions in medical practice in Flanders, Belgium: A nationwide survey. Lancet 2000; 356:1806-1811

11. Burkhardt S, La Harpe R, Harding TW, et al: Euthanasia and assisted suicide: Comparison of legal aspects in Switzerland and other countries. Med Sci Law 2006; 46:287-294

12. Truog RD, Cist AFM, Brackett SE, et al: Rec- ommendations for end of life care in the intensive care unit: The Ethics Committee of the Society of Critical Care Medicine. Crit Care Med 2001; 29:2332-2348

13. Vincent JL: Forgoing life support in western European intensive care units: The results of an ethical questionnaire. Crit Care Med 1999; 27:1626-1633

14. Asch DA: The role of critical care nurses in euthanasia and assisted suicide. $N$ Engl J Med 1996; 334:1374-1379

15. Coda BA: Opioids. In: Clinical Anesthesia. Fifth Edition. Barash PG, Cullen BF, Stoelting RK (Eds). Philadelphia, Lippincott Williams \& Wilkins, 2006, pp 353-383

16. Steinberg A, Sprung CL: The dying patient: New Israeli legislation. Intensive Care Med 2006; 32:1234-1237

17. The Society of Critical Care Medicine Ethics Committee. Attitudes of critical care medicine professionals concerning forgoing lifesustaining treatments. Crit Care Med 1992; $20: 320-326$

18. Eidelman LA, Jakobson DJ, Pizov R, et al: Forgoing life-sustaining treatment in an Israeli ICU. Intensive Care Med 1998; 24: $162-166$

19. Emanuel EJ, Daniels ER, Fairclough D, et al: The practice of euthanasia and physicianassisted suicide in the United States. Adherence to proposed safeguards and effects on physicians. JAMA 1998; 280:507-513

20. Van der Heide A, van der Maas P, van der Wal $\mathrm{G}$, et al: Using potentially life-shortening drugs in neonates and infants. Crit Care Med 2000; 28:2595-2599

21. Overleggoep Toetsing Zorgvuldig Medische Handelen Rond het Levenseinde bij Pasgeborenen: Toetsing als Spiegel van de Medische Praktijk. Ministerie van Volksgezondheid, Welzijn en Sport, 1997

22. Chan JD, Treece PD, Engleberg RA, et al: Narcotic and benzodiazepine use after withdrawal of life support. Chest 2004; 126 : 286-293

23. Edwards MJ: Opioids and benzodiazepines appear paradoxically to delay inevitable death after ventilator withdrawal. $J$ Palliat Care 2005; 21:299-302

24. Quill TE: The ambiguity of clinical intentions. N Engl J Med 1993; 329:1039-1040

25. Quill TE, Lo B, Brock DW: Palliative options of last resort. JAMA 1997; 278:2090-2104

26. Campbell ML, Bizek KS, Thill M: Patient responses during rapid terminal weaning from mechanical ventilation: A prospective study. Crit Care Med 1999; 27:73-77 